\title{
Geographical Analysis of Mobile Network Reception Quality -Signal Strength : A Case Study of Accra Metropolitan Area, Ghana
}

\author{
Alex Barimah Owusu; \\ Department of Geography and Resource Development, \\ University of Ghana, LG 59, Legon, Accra, Ghana
}

\begin{abstract}
Cost of mobile phone communication service in Ghana is seen by many subscribers to be too high when compared to other countries, developed and developing. Despite the cost, mobile usage penetration in Ghana has reached $75 \%$. Perhaps the agonizing part is not how much one pays for the service, rather, the paying for unattained service. In many locations, voice calls are not audible while others fall into dead zones. The argument is that mobile phone service providers need to educate their customers on the signal strength of the subscriber's location before customers subscribe for the service. This study presents the spatial pattern of mobile network reception quality in the AMA. The objective was to identify gaps in coverage using signal strength of two mobile network providers, MTN and TIGO. The study found that MTN had 184 masts transmitting signals within AMA. However there is a considerable concentration of them within the central AMA, accounting for the strong signal strength in areas around Accra Central, Accra Newtown, Kaneshie, Kotobabi, and Adabraka. Major localities of signal gaps for MTN are found around Little Legon, Burma Camp and Mpoase. MTN has three times more subscribers than TIGO. TIGO had 50 masts which are unevenly distributed and concentrated in areas around Darkuman, Kokompe, and Abeka. Generally, TIGO's signal showed stronger from field test, but it has fewer subscribers. TIGO has major gaps in areas around Burma Camp, parts of Dansoman, Chorkor, Korle Gonnor, Little Legon, East Legon towards Adjiringanor, Mpoase and Kwame Nkrumah Circle.
\end{abstract}

Keywords: Geographic Information Systems, Signal Strength, Multi-criteria decision making, Accra Metropolitan Area

DOI: $10.7176 / \mathrm{CER} / 13-1-05$

Publication date: January $31^{\text {st }} 2021$

\subsection{Introduction}

A mobile phone's reception quality is largely affected by one's location (Guinness, 2017; Singh et al., 2012; Ferris et al., 2006). Every object that the signal meets during transmittal from the tower to one's mobile device at a particular location causes some degree of interference. This interference, in many cases leads to loss of signal or reduction in signal strength to the barest minimum and subsequent break in communication, which is known technically as dead zones, dropped calls or poor signal. The term dropped call may also be used when calls terminate unexpectedly because of some technical reasons, which may include the following:

1. Presence of dead zone or an "abnormal release";

2. Loss of signal resulting from distance from the mast;

3. Obstruction due to interference;

4. Mobile phone goes out of network provider's service area;

5. Cellular network architecture;

6. Topography; and

7. Low battery.

Generally, a stronger mobile phone network signal is easy to obtain in an urban area. Unfortunately, within the urban space of the Accra Metropolitan Area (AMA), many customers complain of dead zones, dropped calls or poor signal. Many factors, including land use and cover types, which have changed recently, may be contributing to impedance or interference in signal propagation in AMA and this has resulted in an array of problems ranging from dropped calls, to no service and the subscribers' inability to access information from the internet. The two leading telecommunication firms, MTN and TIGO, have a lot of subscribers within the AMA boundary (NCA, 2013). The problem of dropped calls frustrates MTN and TIGO subscribers. Subscribers complain about paying for unattained services. People are distressed when they are unable to communicate because of a poor signal. For instance, it will be a great distress if due to a poor signal one cannot make a call during an emergency situation such as a fire outbreak or robbery. Thus, this study seeks to answer the following questions:

a. What is the spatial distribution of masts (MTN and TIGO) within the AMA boundary and their signal strength levels?

b. Which locations are likely to have more dead zones when signal strength is modelled based on land use and topography? 
c. Are the modelled dead zones in ' $b$ ' above different from field validated signal in reality using active mobile phone?

Using Geographic Information Systems (GIS) techniques, this study provides answers to these questions and offers a better spatial perspective of the dynamics of signal strength within AMA to educate the subscribers of MTN and TIGO.

\subsection{Signal Propagation and the Role of Location}

Mobile Network Signal Propagation: The signal transmitted or received by a cellular device is known as its reception or service (Shankari et al., 2014). It is measured in decibel-milliwatts ( $\mathrm{dBm})$. Cell phone signal propagation talks about how the cell phone waves move, and has a characteristic referred to as the line of sight. Line-of-sight propagation is a characteristic of electromagnetic radiation or acoustic wave propagation which means waves travel in a direct path from the source to the receiver (Haslet, 2008) and it is usually intercepted by a cellular network transmission tower, also known as the mast. The efficiency of a cellular network tower to the user depends on varying factors, such as the proximity to the tower and the presence of obstruction (Nkordeh et al., 2016; Haslet, 2008), wind velocity and the number of users dependent on a cellular tower. Person (1992) points out that, wireless signals transmitted from the Base Station transmitters are significantly affected by factors, such as proximity to a tower, physical obstructions such as buildings or trees, and the nature of the environment (dense vegetative cover, and steep terrains). The propagation of radio waves is also influenced by many physical mechanisms, including free space loss, terrain blocking and reflection, foliage absorption, ionospheric reflection and absorption, Doppler shift and multipath fading (Matheson et al., 1998). Propagation parameters of mobile signal transmission such as antenna height, tilt, antenna gain, Equivalent Isotopically Radiated Power (EIRP), and transmitting frequency are essential practical and theoretical guides to effective mobile network planning (Uzoma, 2014; Agbaraji et al., 2014; Shankari et al., 2014; Saveeda et al., 2013). Areas where signal strength and reception are negligible to cellular users and cannot be transmitted to nearby base stations are termed as dead zones. Hence, the mobile service is unavailable in such regions. Dead zones can be caused by hilly terrains, dense vegetative zones and geographical distance. Also, mobile signal strength and reception quality can be interrupted or interfered by building materials. Metal-based building materials can absorb radio frequency (RF) signals, and curtail the level of signal strength (Telcoantennas, 2017; Viavi Solutions 2015; Anritsu 2003). Other materials include window insulation, metal roofing and copper plumbing and wiring.

Causes and effects of weak signals on reception quality: In cellular communications, the received signal becomes unstable as it travels through interference layout caused by multipath shadowing owing to obstructions and the distance between the mobile station and the base station (Wang, 2014; Anritsu, 2003; Kaveh et al., 2001). In addition, the weather may cause interruptions in signals being emitted from base stations due to changes in mobile signal propagation caused by thunderclouds, precipitation, and temperature inversions. Hence, these result in weak signal thereby acting as a barricade on reception quality. Mobile phones communicate using radio waves, which travel through the air (Guinness 2017). Radio waves, however, are easily interrupted as they are sent through free space to the receiver (RNSA 2017), which affects the reception quality. Other causes of weak signals include network usage and load, poorly deployed antennas and spectrum channel limitations (Guinness 2017). The interference in signal affects reception quality through call drop-outs, digital garbling, difficulty hearing other callers and slow mobile internet connections.

The role of location in signal strength: The location of a device is important because it has an effect on the signal strength. There exists a direct relationship between the location of a cellular user and a base station, such that the closer a base station is to a mobile user the higher the probability of strong signal and vice versa (Whitwam, 2010). According to Guinness (2017) and Wang (2014) one's cell phone signal gets weaker the more the atmosphere the signal has to move through. Also, Singh et al (2012) propounded that being aware of the location of a device could either improve the performance of a communication network, or it could also be used to implement services relying on location information. Similarly, the number of people connecting to a cell tower (mast) at a particular location and time can affect the cell's signal strength. Guinness (2017) stated that cell towers are only designed to handle a certain number of connections at once. Most of the time, masts got more connections than their designed capacity. The terrain of the location could also affect the signal strength. Guinness (2017) further added that, if there's something grand in the way, like a hill or mountain range, the radio waves will find it impossible to reach the tower and the mobile phone user. Also land use and land cover characteristic and elevation may enhance or reduce signal strength.

\section{Methodology}

\subsection{Study Area}

This study was conducted in the AMA, Ghana. AMA is bounded by the Gulf of Guinea to the south, by the University of Ghana to the north, by Tema Municipal Area to the east and by Korle Lagoon to the west. Below is figure 1 , showing the map of the study area. 


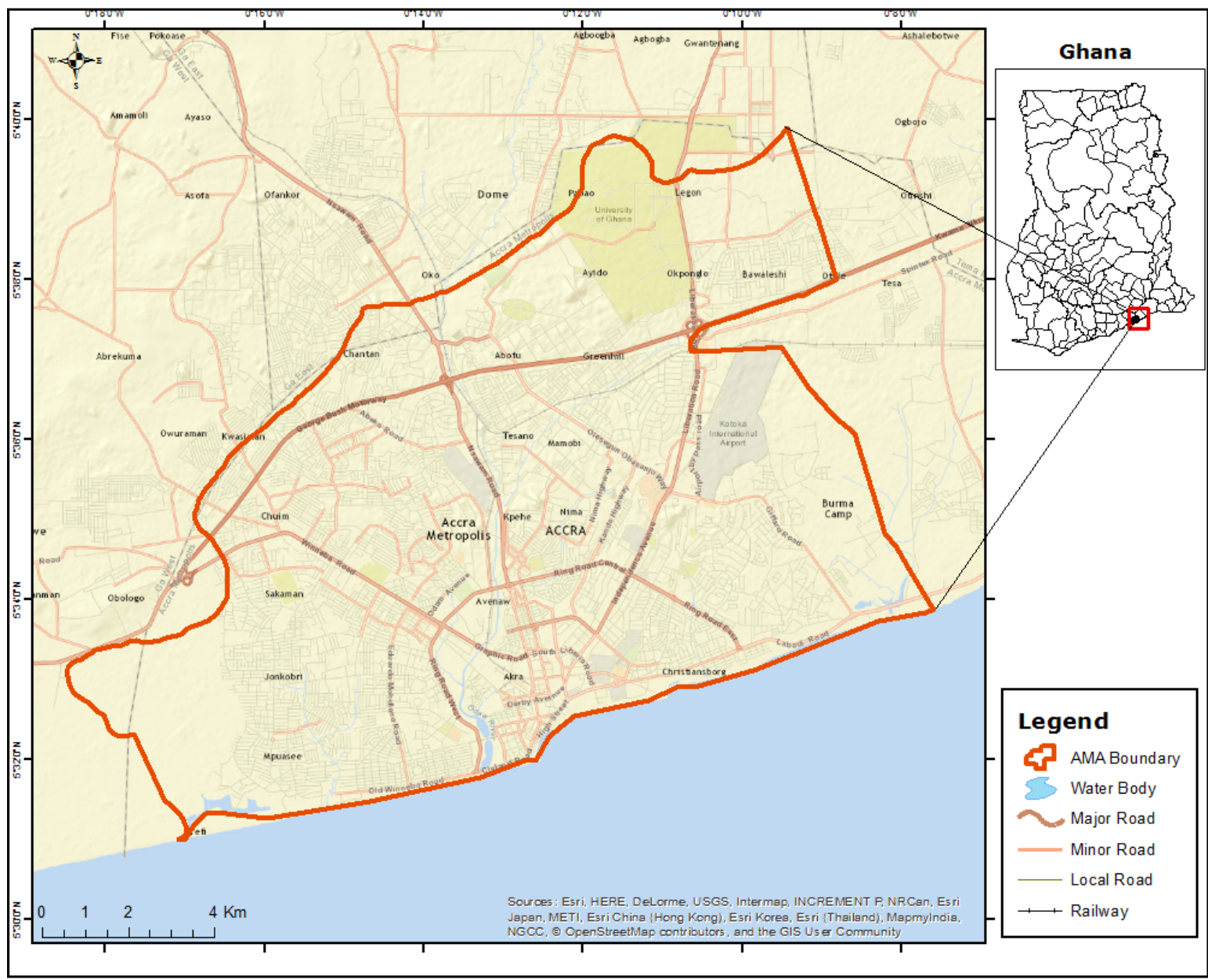

Figure 1: The study area - Accra Metropolitan Area (source: Author, 2017)

The AMA stretches from about $25 \mathrm{~km}$ east to west and about $12 \mathrm{~km}$ north to south. AMA has an estimated population of $1,848,614$, with $887,673(48.02 \%)$ males and 960,941(51.98\%) females, according to the 2010 population census (Ghana Statistical Service, 2012). Analysis of the demographic characteristics of the area shows that AMA has remained the most ethnically diverse and densely populated district in Ghana since 1960. AMA is the most urbanized district in the Greater Accra Region. It also has the highest literacy rate of $85.1 \%$. Over $68 \%$ of the population aged 15 years or older is economically active. The economically active population of AMA is estimated to be 823,327 . However, the daily influx of people from dormitory towns will make the figure higher than estimated. A lot of commercial activities are concentrated within AMA with almost all major businesses in Ghana having their headquarters located there. AMA is a major centre for manufacturing, marketing, finance, insurance, transportation and tourism. As an urban economy, the services sector is the largest, employing about 531,670 people. The second largest, secondary sector, which comprises light and heavy manufacturing, employs $22.3 \%$ of the labour force (that is 183,934 people). Accra has 114,198 of its labour unemployed, resulting in an unemployment rate of $12.2 \%$ (Ghana Statistical Service, 2012). The extent of urbanization and the level of illiteracy coupled with trading and business activities have created a burgeoning market of mobile phone user for mobile network operators to the level unparalleled by any part of Ghana.

AMA lies in the Coastal Savannah ecological zone. There are two rainy seasons. The average annual rainfall is about $730 \mathrm{~mm}$, which falls primarily during the two rainy seasons. The first begins in May and ends in mid-July. The second season starts in mid-August and ends in October. Rain usually falls in intensive short storms and gives rise to local flooding where drainage channels are obstructed. The temperature barely varies throughout the year. The mean monthly temperature ranges from $24.7^{\circ} \mathrm{c}$ in August (the coolest) to $28^{\circ} \mathrm{c}$ in March (the hottest) with an annual average of $26.8^{\circ} \mathrm{c}$ (AMA 2015; AMA 2013). As the area is close to the equator, the daylight hours are uniform during the year. Relative humidity is generally high varying from $65 \%$ in the mid-afternoon to $95 \%$ at night. The predominant wind direction in Accra is from WSW to NNE sectors (AMA, 2013). Wind speeds normally range between 8 to $16 \mathrm{~km} / \mathrm{hr}$. High wind gusts occur with thunderstorm activity, which passes in squalls along the coast. The maximum wind speed record in Accra is $107.4 \mathrm{~km} / \mathrm{hr}$. (58 knots). High winds associated with thunderstorm activity often cause damage to property by removing roofing material. Several areas of Accra experience micro climatic effects. Low profile drainage basins with a north-south orientation are not as well 
ventilated as that orientated east-west. Air is often trapped in pockets and an insulation effect gives rise to a local increase in the air temperature by several degrees.

There is ecological evidence to suggest the vegetation of the metropolitan area has been altered in the more recent past century by climate and human factors. Much of the metropolitan area was believed to have been covered by dense forest of which only a few remnant trees exist. A climatic change combined with the gradient of the plains and cultivation has imposed vegetation structures like those of the Southern Shale, Sudan and Guinea Savannahs all of which lie north of the Accra plains. Shrub land, grassland and coastal lands make up the three broad vegetation zones in the metropolitan area. Only the shrub land occurs more commonly in the western outskirts and in the north towards the Aburi hills. It consists of dense clusters of small trees and shrubs, which grow to a height not exceeding five meters. The grasses are a mixture of species found in the undergrowth of forests. They are short, and rarely grow beyond one meter. The coastal zone comprises two vegetation types, wetland and dunes. In addition to the natural vegetation zones, several introduced trees and shrubs thrive in the metropolitan area (Owusu 2018; AMA, 2013). The vegetation height does not interfere with radio signal propagation.

AMA is situated in an area that is generally low-lying and slightly undulating in some places. The topography is generally gently undulating. A few prominent boulders are scattered irregularly over the area, with the higher part being about 240 meters above sea level (Owusu, 2018). The rest of the area is about 60 meters above sea level. The geology of AMA consists of Precambrian Dahomeyan schists, granodiorites, granites gneiss and phonolites to late Precambrian Togo series comprising mainly quartzite, phyllites, phylitones and quartz breccias. Other formations found are the palaeozoic accraian sediments - sandstone, shales and interbedded sandstone-shale with gypsum lenses. The coastline of Accra comprises a series of resistant rock outcrops and platforms and sandy beaches near the mouth of the lagoons. The Accra Metropolitan drainage catchment area extends from the eastern boundary of the Nyanyanu catchment on the west of the Greater Accra regional boundary to Laloi east of Tema.

\subsection{Data Collection}

Data for this research was gathered from primary and secondary data sources. The primary sources included Global Positioning Systems (GPS) mapping of selected locations, testing for signal strength from iPhone 6S plus and Samsung Galaxy S6 and mapping of network mast locations. Two different cell phones were used to test for consistency, since signal strength at different locations may be affected by the type of phone used. In addition, questionnaires were administered to residents of selected communities where signal strength is either weak or strong. Secondary data was gathered from review of relevant literature, articles, journals, magazines, and websites. Other materials reviewed included land use and land cover data, digital elevation data, mast height specifications and AMA boundary. Various forms of GIS data used for spatial analysis is listed in Table 1 below:

Table 1: Spatial data, type, source and accuracy

1. Digitized boundary, roads and towns

2. Elevation/slope (Digital Elevation Model)

3. Land use data

4. Masts characteristics and height

Type

Shapefile

Raster

Shapefile

Spreadsheet
Source

RS/GIS lab, University of Ghana

RS/GIS Lab University of Ghana

RS/GIS lab, University of Ghana
Reime Ghana Limited
Accuracy

$85 \%$

$95 \%$

$85 \%$

$90 \%$

The study sought to validate the results of the analysis with mobile phone users' experience within their community of residence in terms of signal strength. Respondents were sampled using the systematic sampling technique. The systematic sampling technique helped to obtain a representative and statistically valid sample for the study area. It also has the advantage of uniformity and good coverage of AMA. A total sample of 100 respondents was selected from AMA. The selection of the sampled communities of AMA was based on the results of low and high signal obtained from the GIS spatial analysis performed. We selected ten communities including five low and five high signal strengths respectively. The respondents were given questionnaires to answer in relation to their experience of dropped calls and dead zones. Respondents also answered questions relating to frequency of occurrence and time of day they experience dropped calls. The range of questions included both closed and open ended question. For example respondents answered questions like 'how often do you experience dropped calls in your house or area? Which times of day are dropped calls high? and many others. The main purpose was to solicit their view and use it to confirm or reject the results of the GIS analysis.

\subsection{Data Processing}

There were two types of data analysis:

1. Analysis of spatial data

2. Analysis of the non-spatial data collected with questionnaires.

The analysis of the spatial data was in three phases;

a. Preparation of masts locations to show the spatial distribution of masts in AMA

b. Modelling of signal strength to show spatial variations of signals in AMA and 
c. Modelling of mobile phone signal to validate the actual signal strength on the ground.

(a). Spatial distribution map preparation entailed the conversion of the GPS locations of the masts for MTN and TIGO into latitude and longitude positions and projecting the data into geographic coordinates using WGS84, and UTM zone 30N. Subsequently, the data was imported into the ArcMap software and additional data added as a layer to make it possible to check for positional accuracy as well as editing where necessary.

(b). The modelling of signal strength was done taking into consideration all factors that cause interference in signal from the mast to the cell phone. However, certain factors were held constant. These include low battery, mast quality and cell phone quality. Equation 1 shows the mathematical model used for the signal strength modelling. This shows that signal strength is a function of mast distribution aided by elevation, however, obstruction may contribute negatively by reducing signal strength and in some cases creating dead zones.

Signal Strength Received = (mast distribution+Mast height + Elevation - obstruction (land Use)) (1) Indicators used in the GIS analysis include the following: mast distribution, mast height, elevation and land use. Mast height was added to elevation to give the height of signal propagation. Furthermore, 3D Analysis tools such as Viewshed analysis were used to include the slope effect and possible obstruction from land use and land cover types. Finally, Inverse Distance Weighting (IDW) was performed to interpolate signal coverage. These indicators determined the spatial variation of signal strength with respect to the locations and heights of the masts.

(c). Field Validation Data collected with i-Phone 6S Plus and Samsung Galaxy S6 and GPS.

Cell Phones are known to use radio signals, which according to CDI (2016), are indicated by the "Received Signal Strength Indicator" (RSSI) measured in - dBm (Table 2). CDI (2016) further states that Signal Strength runs from $-51 \mathrm{dBm}$ to $-113 \mathrm{dBm}$. Values closer to $-51 \mathrm{dBm}$ are stronger. However signal values of $-98 \mathrm{dBm}$ and beyond are considered not strong enough for a proper functioning network.

Table 2: Signal Strength Measuring scale

\begin{tabular}{|l|l|}
\multicolumn{1}{|c|}{ RSSI } & \multicolumn{1}{c|}{ Signal Strength } \\
$>-70 \mathrm{dBm}$ & Excellent \\
\hline$-70 \mathrm{dBm}$ to $-85 \mathrm{dBm}$ & Good \\
\hline$-86 \mathrm{dBm}$ to $-100 \mathrm{dBm}$ & Fair \\
\hline$<-100 \mathrm{dBm}$ & Poor \\
\hline$-110 \mathrm{dBm}$ & No Signal \\
\hline
\end{tabular}

Source: CDI 2016

\subsection{Analysis and Results}

\section{Modeling of Signal Strength Using Multicriterial Decision making Algorithm}

Elevation impacts signal strength: Elevation has two impacts on signal propagation. The first impact is caused by the ground elevation of the area. The second impact is caused by the elevation of the mast (i.e. the height of the antenna). The actual mast height is elevation plus antenna height. Elevation of the area affects network reception quality, but most importantly the height of the mast is key to signal propagation. A summary of mast height is indicated in Table 3. MTN masts height range between 8 meters and 110 meters whiles TIGOs highest mast was 45 meters and lowest is 4 meters.

Table 3: Mast Height of MTN and Tigo networks

$\begin{array}{lll}\text { Provider } & \text { Highest (meters) } & \text { Lowest (meters) } \\ \text { MTN } & 110 & 8 \\ \text { TIGO } & 45 & 4\end{array}$

Source: Reime Ghana Limited (2016)

The elevation of the study area ranges from zero at the mean sea level to about 300 meters around Legon hills (Great Hall, University of Ghana). Most of the masts are sited to take advantage of isolated peaks in AMA including Legon hills (north, north-east part of the map). Figure 2 shows the digital elevation model (DEM) of AMA, representing the general pattern of elevation in AMA. The elevation data was 90 meters resolution Shuttle Radar Topography Mission (SRTM) data from NASA. The data is spatially referenced. Elevation affects signal propagation by either enhancing or obstructing signals. Again, slopes may create gaps in signal reception. 


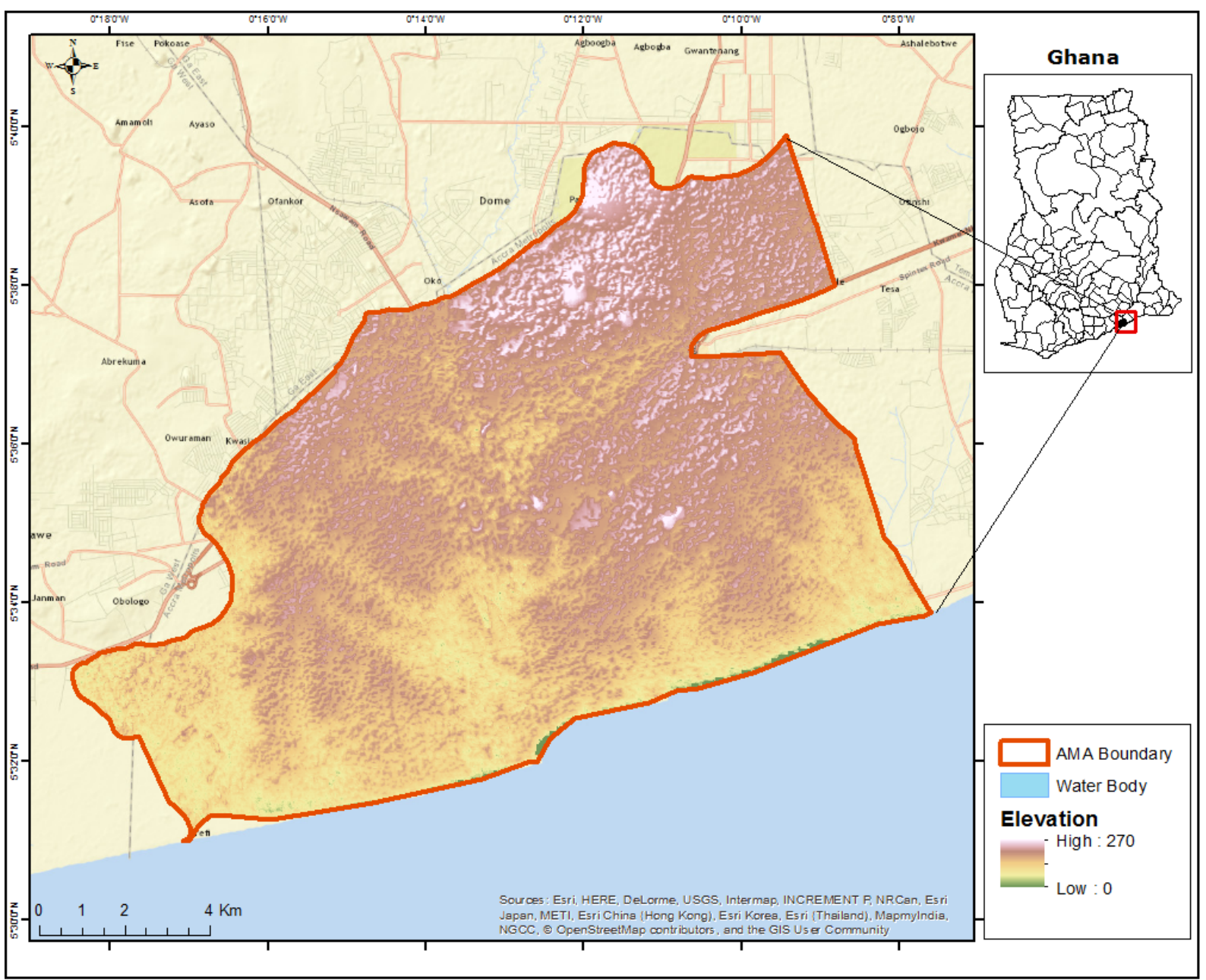

Figure 2: Elevation of the study area (source: Author 2017)

Land Use: One variable that can affect mobile network signal propagation in an urban environment is land use. Land use planning refers to all activities associated with the management of land and its uses, whether it is considered as an environmental, an economic and a socio-cultural resource. Land use therefore includes land tenure, the implementation of land policy, land administration, and land readjustment (Williamson, 2001). It has been posited that land reform is concerned with changing the institutional structure governing man's relationship with the land, involving intervention in the prevailing pattern of land ownership, control and usage in order to change the structure of holdings, improve land productivity and broaden the distribution of benefits (Hart et al 2012). The land use of AMA is predominately residential and commercial or economic. However, a small segment of the study area, found in the northern part of the study area, is devoted to forest reserve (Achimota Forest Reserve). As a result, telecommunication masts would not be erected at certain locations within the boundary of AMA, if the urban land planning regime is followed to the letter, thereby influencing mast distribution, as well as the level of signal propagation. Mast sites are essential to telecommunication. Land use affects the siting of masts and also interrupts signal propagation. However, the study shows that the locations of masts belonging to both MTN and TIGO may not have affected signal strength that much under the urban land planning regime of AMA. Therefore, land use cannot strictly inhibit or interfere with mobile network signal strength within AMA but there are some pockets of interference that may have occurred. In spite of this observation, both MTN and TIGO have erected mast of varying heights at different locations to avert interference. However, MTN masts are taller, they are many and are of different range of heights (see table 3). This gives MTN better signal than TIGO.

Viewshed and Inverse Distance Weighting: Viewshed analysis is a visual impact analysis tool in GIS, which uses digital elevation model (DEM) data. It can also be used to identify visibility between two features on a landscape or for identifying the exposure of one feature across a landscape (Green, 2009). Exposure in this case refers to signal propagation which in turn affects mobile network signal reception. Mobile network signals decrease when they are propagated in the air just as visible lights do (Zheng and Ni, 2010).

Inverse Distance Weighting (IDW) is distance based interpolation method used in determine a cell's exposure. It determines cells exposure values using a linear-weighted combination set of sample points (measured value). The weight assigned is a function of the distance of an input point from an output cell location. The greater the 
distance, the less influence the cell has on the output value. The meaningful value for mast locations in this study is the elevation of the masts. Thus the average of all mast elevations has local influence that diminishes with distance. The mean elevation of masts is 30 meters. Tables 4 and 5 represent reclassified Viewshed and interpolated IDW cell values for both MTN and TIGO.

Table 4: Reclassified Viewshed Cell Values

\begin{tabular}{|l|l|l|l|}
\hline Reclass & Cell Value(MTN) & Cell Value(TIGO) & Signal Strength \\
\hline 1 & $0-18.25$ & $0-4.5$ & Poor \\
\hline 2 & $18.25-36.5$ & $4.5-9$ & Average \\
\hline 3 & $36.5-54.75$ & $9-13.5$ & Good \\
\hline 4 & $54.75-73$ & $13.5-18$ & Very Good \\
\hline
\end{tabular}

Table 5: IDW Interpolated Cell Values for MTN and TIGO

\begin{tabular}{|l|l|l|l|}
\hline Reclass & Cell Value(MTN) & Cell Value(TIGO) & Signal Strength \\
\hline 4 & $3.0601-25.7458$ & $4.0004-19.1559$ & Very Good \\
\hline 3 & $25.7458-31.5203$ & $19.1559-33.2095$ & Good \\
\hline 2 & $31.5203-48.8440$ & $33.2095-47.4832$ & Average \\
\hline 1 & $48.8440-108.239$ & $47.4832-60$ & Poor \\
\hline
\end{tabular}

The two analyses indicate that MTN shows stronger signal in AMA than TIGO. The spatial distribution of masts shows that MTN has 184 masts whilst TIGO has 50 masts within the AMA boundary (Figure 3 and Figure 4 respectively). MTN masts cover the entire AMA and land use types do not hinder their locations. Figure 3 shows the distribution of MTN masts overlaid on classified land cover/land use classes in AMA. Even though the masts are fairly distributed across the study area, the central business area of AMA (indicated by red dotted line) seems to have a very dense cluster of MTN masts.

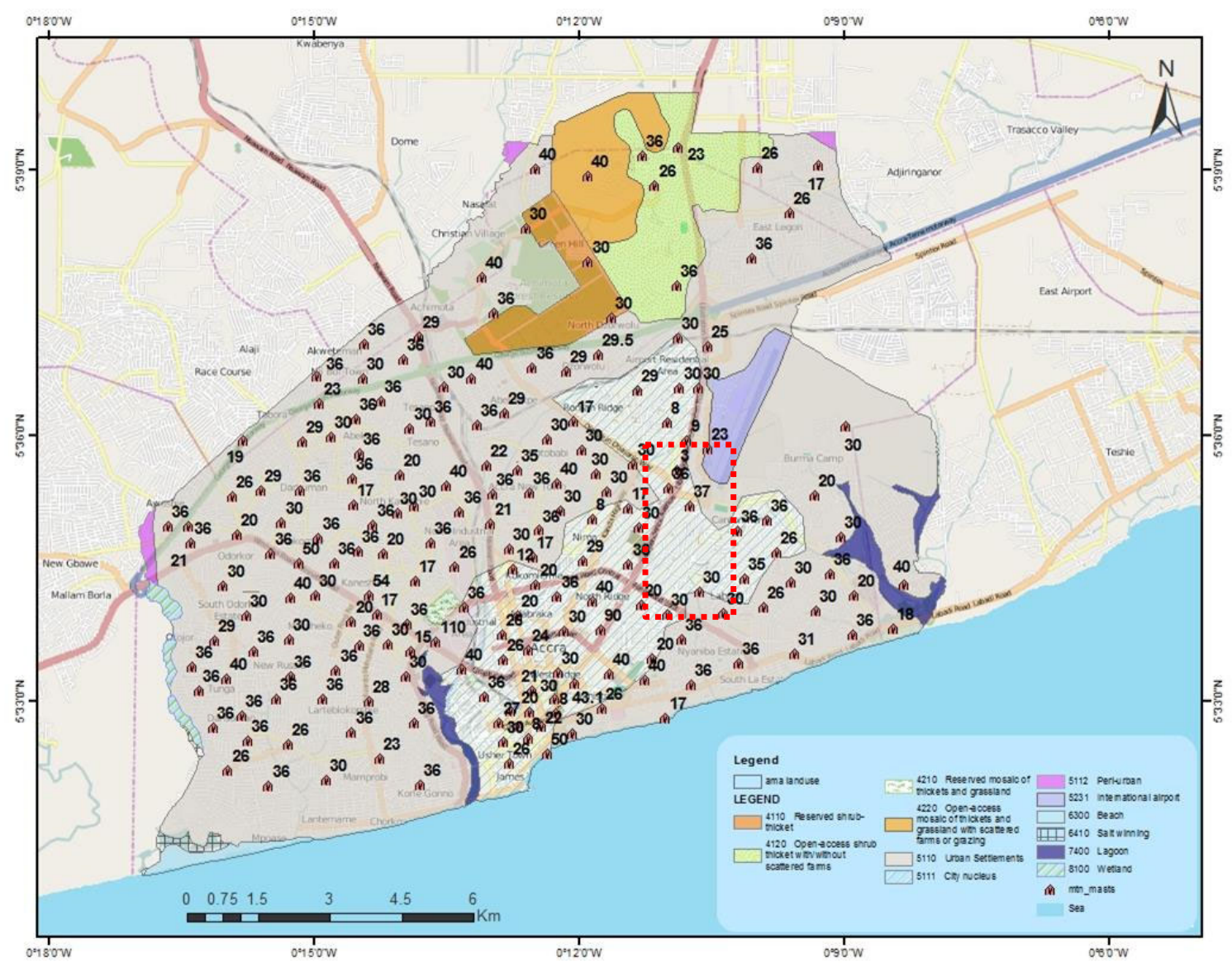

Figure 3: MTN Mast distribution in AMA 2016 (source: Author 2017)

Figure 4 shows the distribution of TIGO masts. The map shows that TIGO masts are not as many as MTN and the masts avoid certain places particularly the south south-west (SSW) and north and North-East (N, NE) including Abeka, Achimota and Legon. 


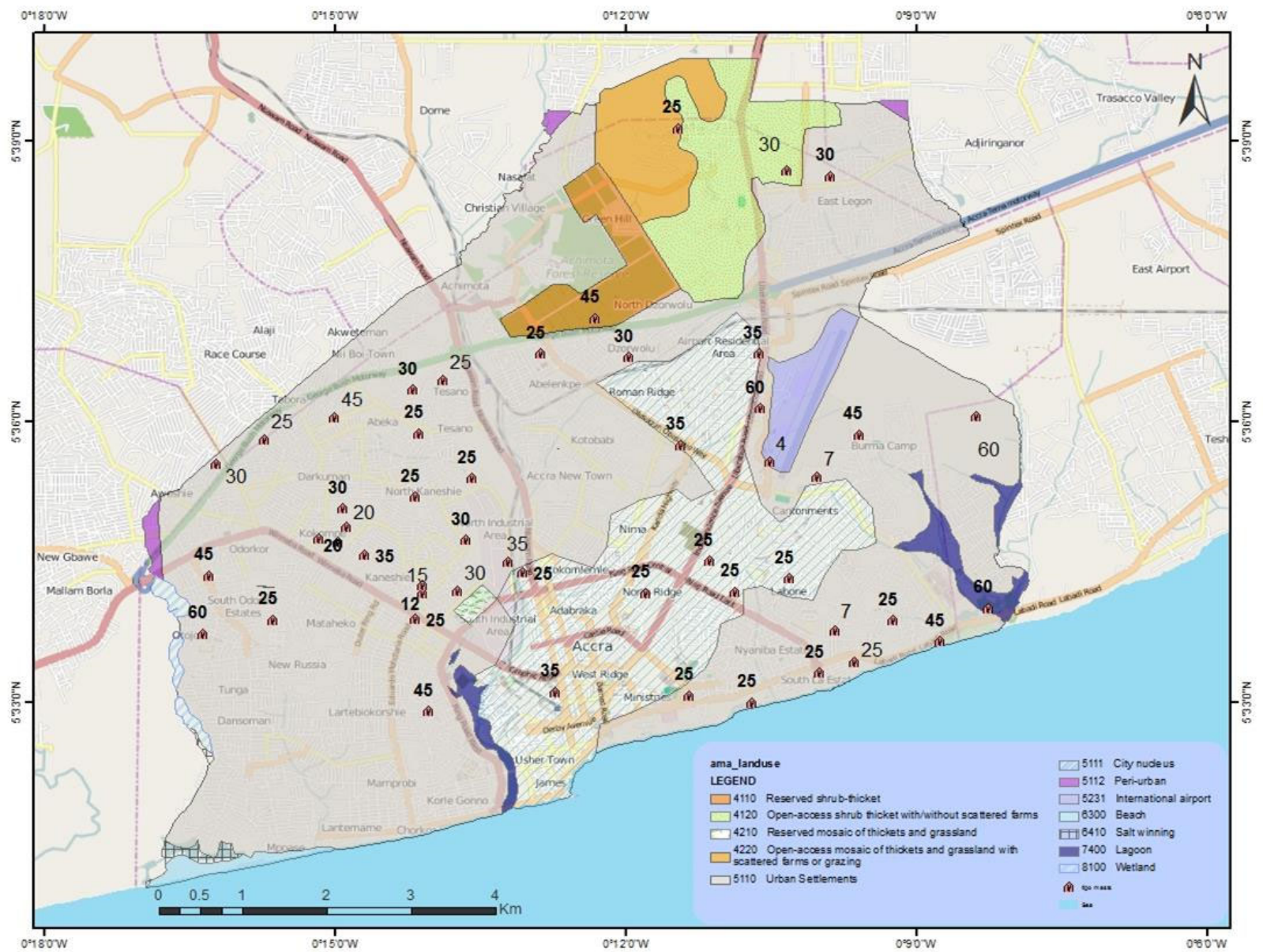

Figure 4: TIGO Mast Distribution in AMA 2016 (source: Author 2017)

The final signal strength analysis was a map generated by combining the Viewshed analysis map and IDW map. The Viewshed map produced cell values which were assigned a weight based on the intensity of visibility of the masts using the Spatial Analyst Tool. The Viewshed indicates signal area of visibility with no interruption (Table 4). The same was done for the values generated by IDW indicated in Table 5. The IDW is an interpolation from each mast based on actual height, including the tower and elevation. This helps in estimating the coverage by each tower. The IDW uses a distance decay function to interpolate the signal strength of each location based on its distance from tower to tower. Combining IDW with Viewshed which is visibility and presence of barriers, we can estimate the possible signal strength. Raster Calculator was used to combine both Viewshed and IDW to produce the final Signal Strength Maps for MTN and TIGO. The prepared maps are shown in Figures 5 and 6 for MTN and TIGO respectively. 


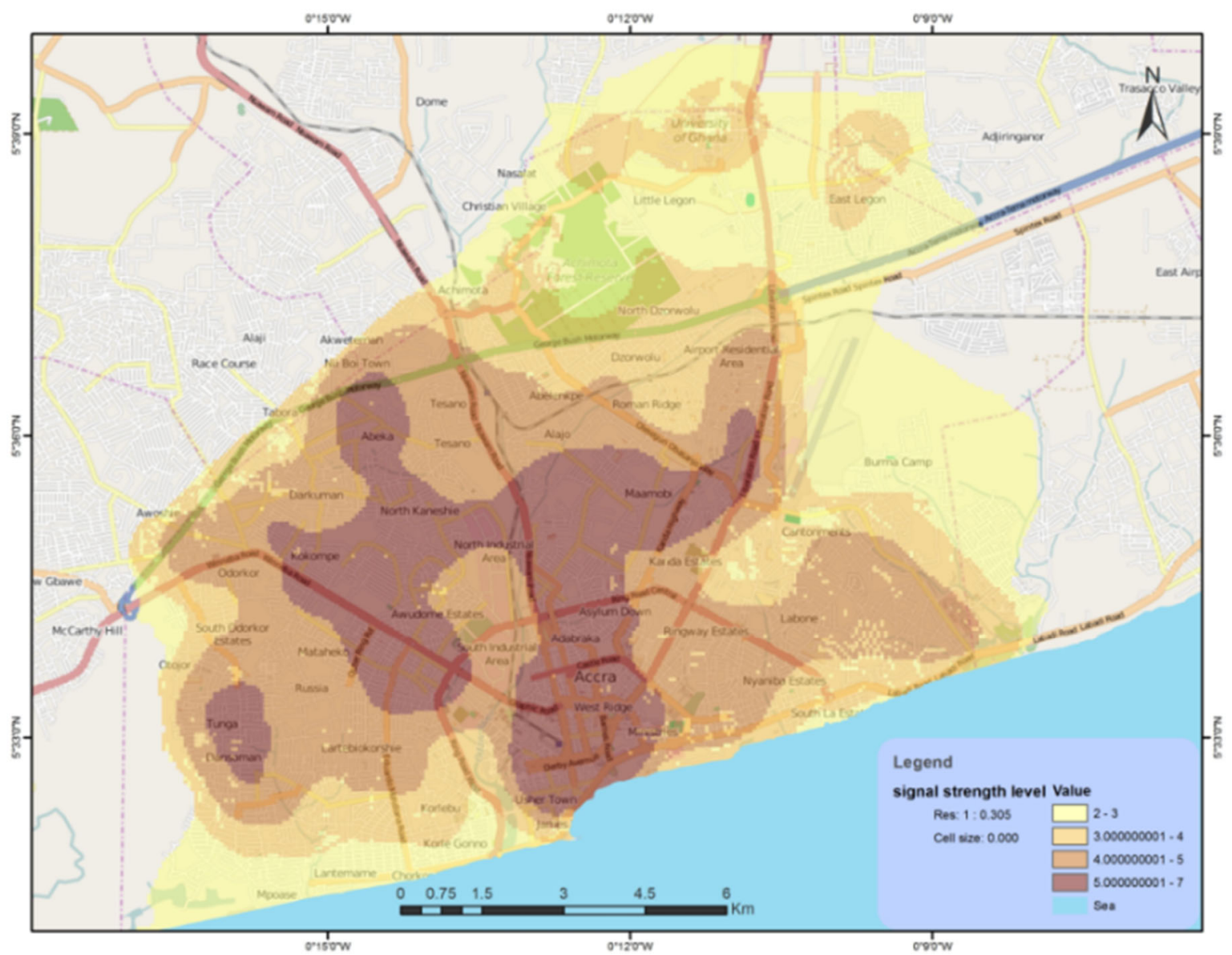

Figure 5: The strength Map of MTN (source: Author 2017)

The significant concentration of MTN masts within central AMA accounts for strong signal in areas around Accra Newtown, Kaneshie, Kotobabi, and Adabraka. Major areas of gaps for MTN are found around Little Legon (north, north-east of the map), Burma Camp and Mpoase. 


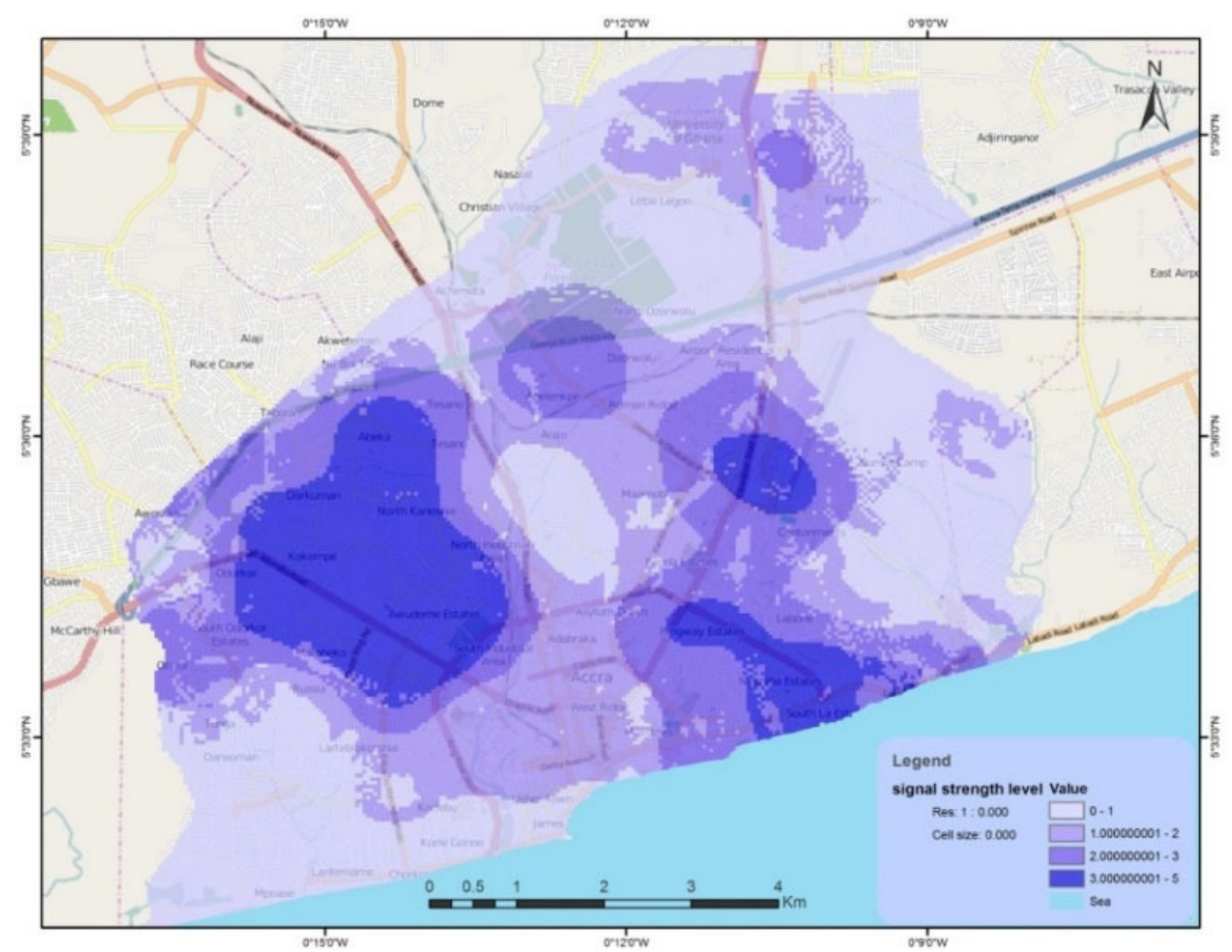

Figure 6: Signal Strength Map (TIGO) (source: Author 2017)

TIGO on the other hand had 50 masts which are unevenly distributed and more concentrated in areas around Darkuman, Kokompe, and Abeka (east of study area). TIGO's signal strength is therefore better in those areas. Major areas of gaps for TIGO are found around Burma Camp, parts of Dansoman to Chorkor, Korle Gonnor, Little Legon, East Legon towards Adjiringanor Mpoase (north, North-east) and Kwame Nkrumah Circle Central part of the map).

\subsection{Field Validation of Signal Strength}

The study sought to validate the modelled signal strength using the cell phone as a field testing device to test the actual signal strength measured or received by the phone. The procedure which was followed was outlined by CDI (2016) as follows:

1. Testing using APPLE I-Phone 6S Plus devices: Turning Apple I-phone into Field Test Mode follows these steps.

Step 1: open the Phone and switch to the keypad

Step 2: dial the following code: $* 3001 \# 12345 \# *$ and then press call.

The I-Phone opens in Field Test Mode and the numerical value for signal strength appears in the upper left-hand corner of the screen where the signal strength was previously displayed in bars. To exit and return the I-Phone to normal status, just hit the Home button. According to CDI (2016) this mode is available on any I-Phone running iOS 4.1 and all later versions.

2. Field Testing Using ANDROID Samsung Galaxy S6 devices: Follows these steps: "Settings" > "About Phone"

The numerical signal strength appears under either Network or Status, depending on the model of the phone you are using.

In this research both Apple I-Phone 6 and Samsung Galaxy 6 S series were used and the average signal strength for the two readings at every location sampled were used. Figure 8 is the IDW interpolated surface showing geographic pattern of signal strength within AMA using figures collected from cell phones. In Figure 6, we show the field signal strength map for MTN. Generally, MTN has low field signal strength compared to TIGO. MTN signal strength curve, plotted from the sampled communities is presented in Figure 7. The field validated interpolated surface of signal strength for MTN shows that strong MTN signals are found in areas around Abeka, Adabraka, Burma Camp, Kokompe, Korle Gonno and Kwame Nkrumah Circle. The strong MTN signal in those 
locations is depicted by the trend line on the high signal plot showing round markers (Figure 7).

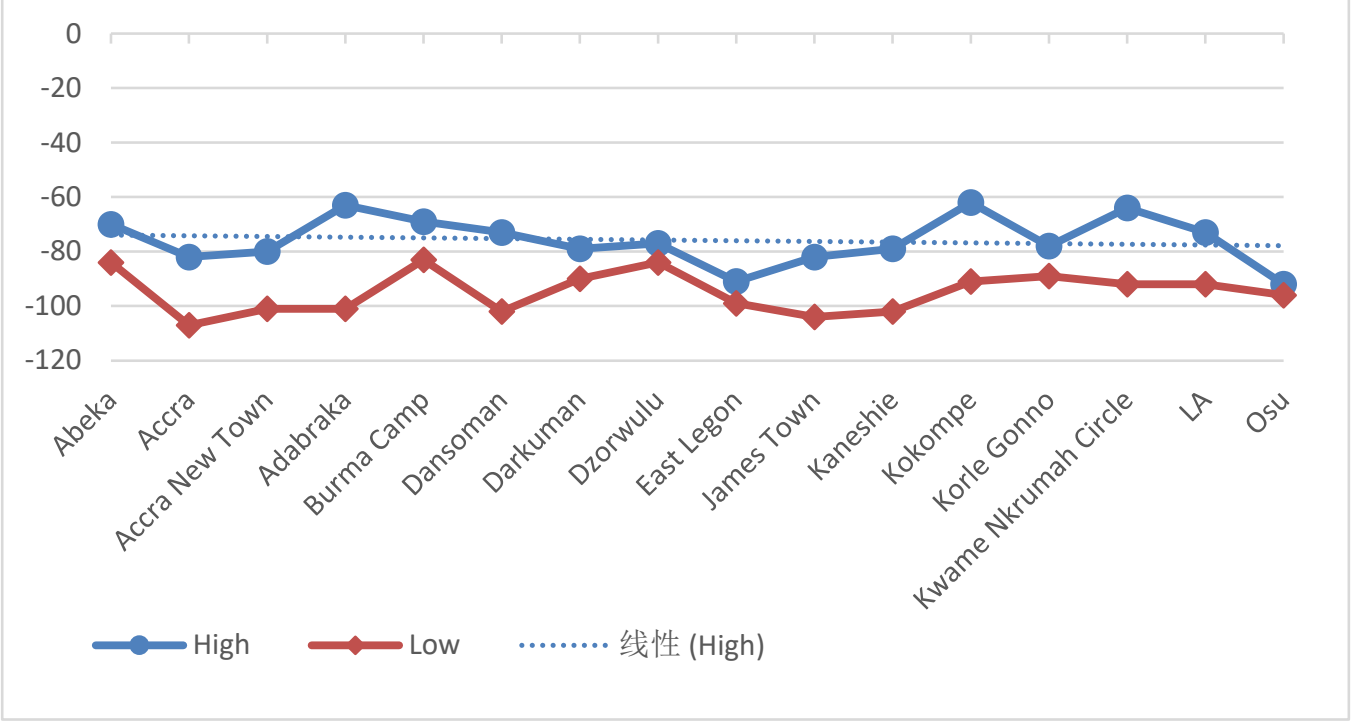

Figure 7: Signal Strength Line for MTN (source: Author 2017)

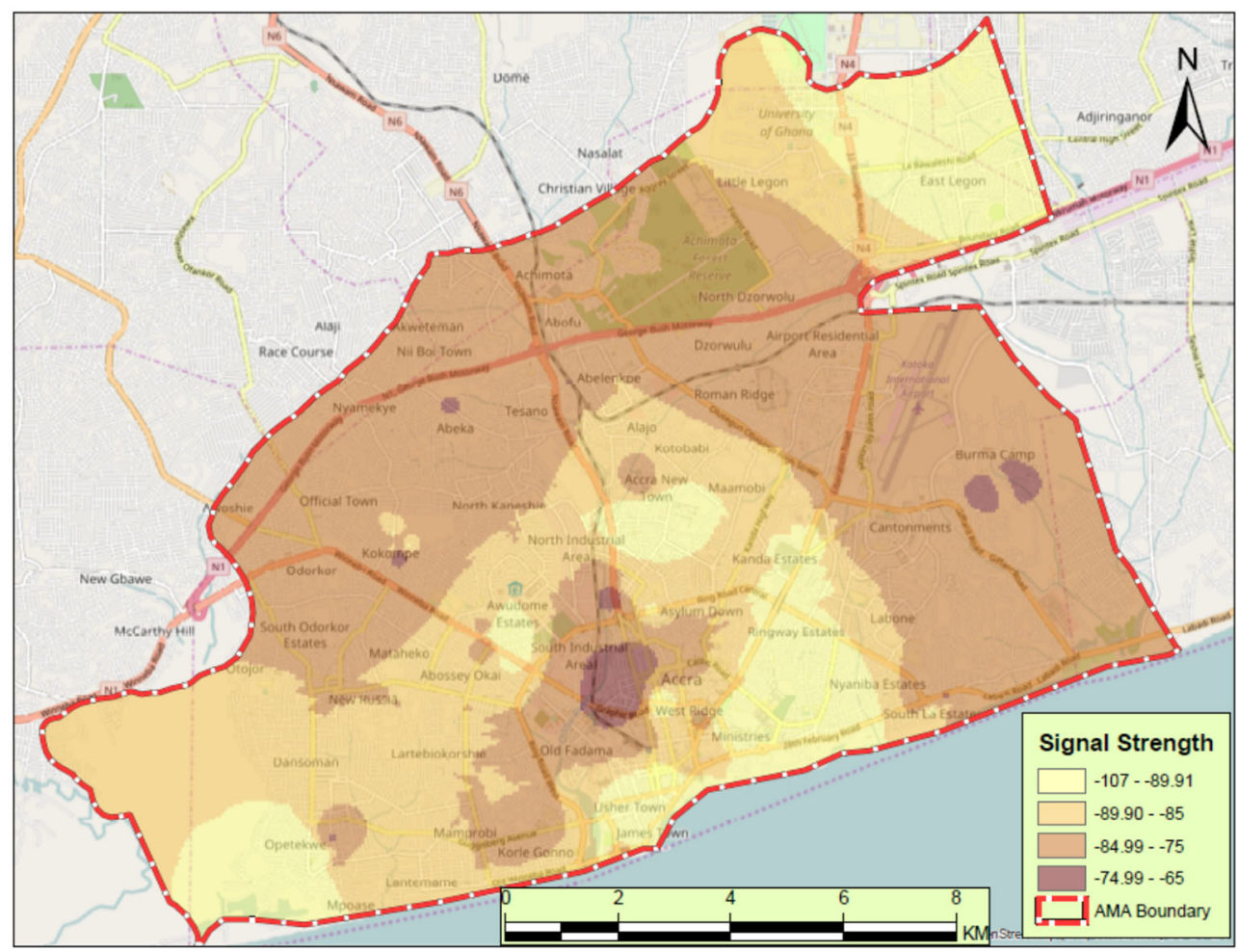

Figure 8: Actual MTN Signal Strength Surface (source: Author 2017)

As noted earlier, CDI (2016) contends that a signal strength lower than $-98 \mathrm{dBm}$ is too weak to sustain calls. Hence locations of such signal are more likely to experience dropped calls or dead zones. Several locations in AMA on the MTN network are likely to suffer from dropped calls. Such locations include Accra Central, Accra New Town, Adabraka, James Town, Kaneshie and Osu. This is depicted by the signal strength below the -100 dBm line. Figure 9 represents the signal strength of TIGO. Interestingly, TIGO appears to have stronger signals in AMA than MTN. 


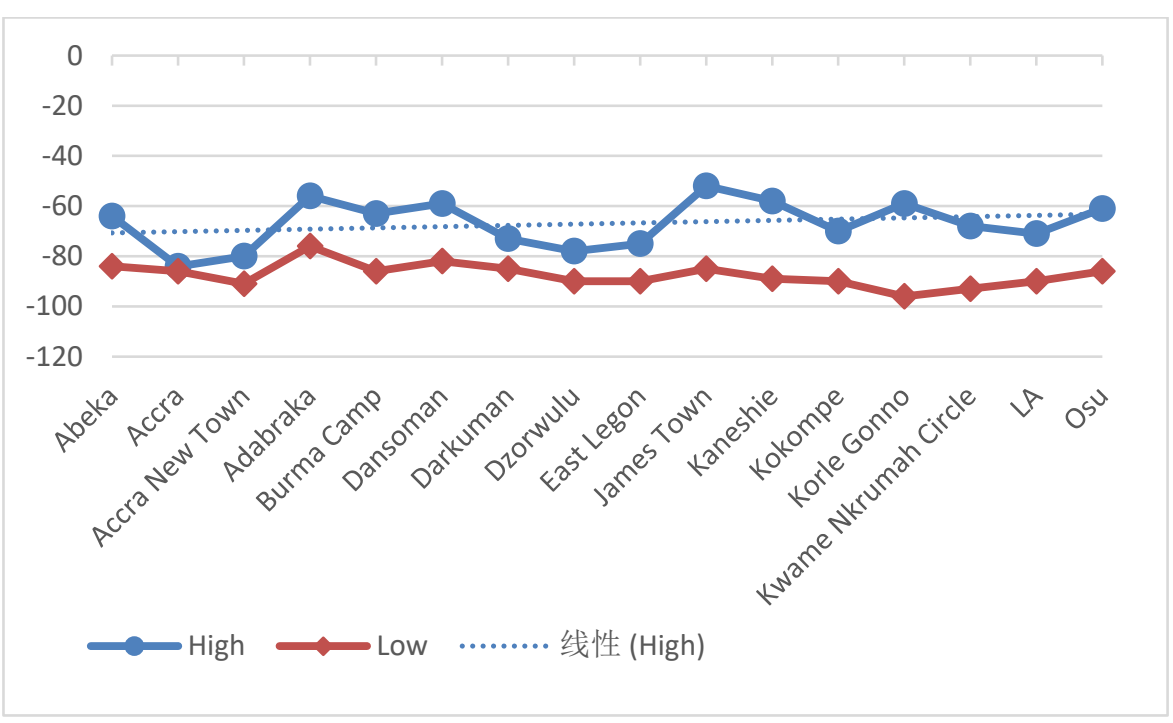

Figure 9: TIGO signal Strength Curve (source: Author 2017)

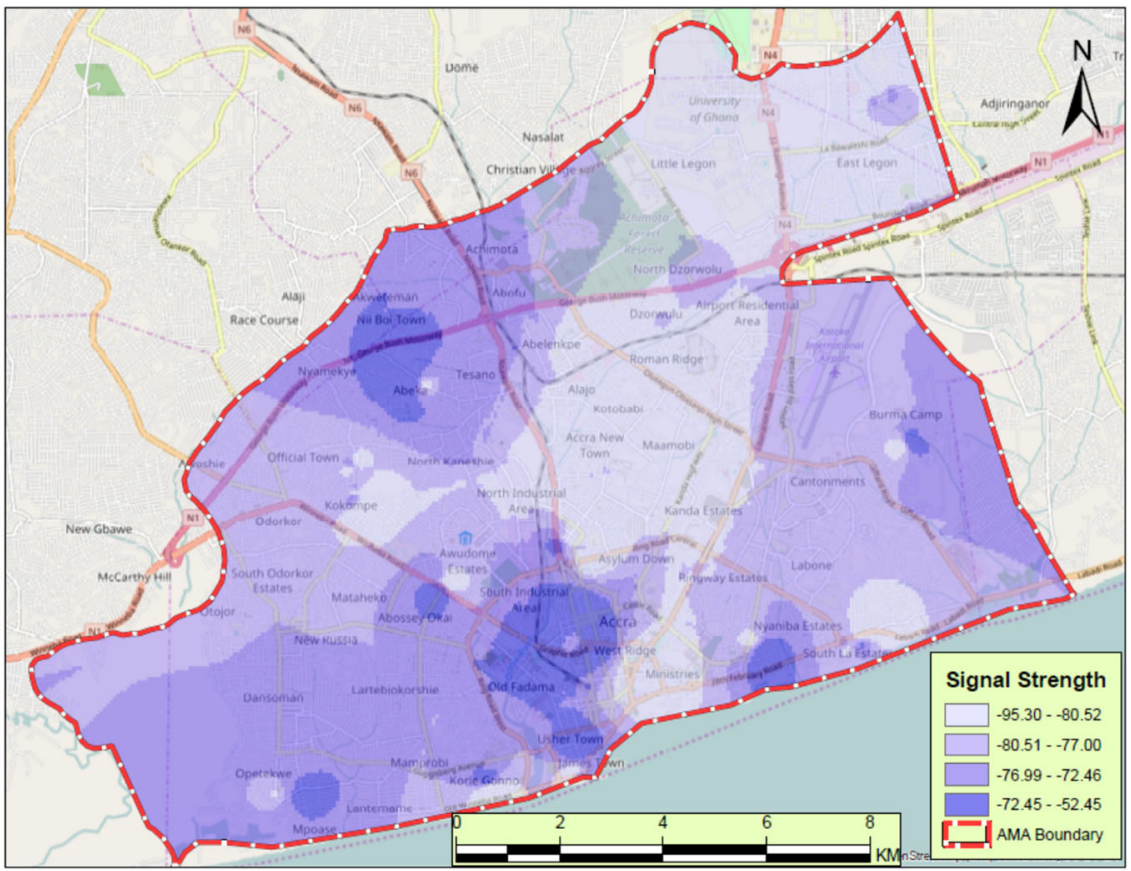

Figure 10: Actual TIGO Signal Strength Surface (source: Author 2017).

Among the communities sampled, there is no community where TIGO's signal goes below $-98 \mathrm{dBm}$. The lowest signal was $-96 \mathrm{dBm}$ and was recorded in Korle Gonno. Comparatively, MTN has signal strength above $100 \mathrm{dBm}$ recorded in seven (7) out of the sixteen (16) GPS mapping communities. The strongest signal for MTN was $-63 \mathrm{dBM}$ which was recorded in Adabraka. TIGO on the other hand recorded signal strengths below $-60 \mathrm{dBm}$ in seven (7) out of the sixteen (16) communities. Very strong TIGO signals were recorded in Adabraka, Dansoman, Burman Camp, James Town and Kaneshie (Figures 9 and 10).

\subsection{Discussion and Conclusion}

This is considered an exploratory study to assess and educate mobile phone network subscribers and network providers, without prejudice. There is much needed education on the signal strength of the two network providers, MTN and TIGO within AMA as a way to help them improve the quality of service. An attempt was made to appraise factors influencing signal strength such as land use as well as the spatial distribution of telecommunication masts belonging to MTN and TIGO and their impact on signal strength within AMA. The study found MTN to have sited more than twice the masts of TIGO in the area, thereby showing better spatial distribution of masts (figures 3 and 4). These masts are fairly distributed across the study area, although the CBD area (Accra Central) seems much denser. Interestingly the CBD area also has higher population concentration. The results from the 
model suggest that the CBD area has stronger signal, conversely the field validation shows that the area has weaker signal. This observation may be explained in terms of possible large number of subscribers connecting to masts at any point in time at that location. This collaborates with the statement by Guinness (2017), who argued that the number of people connecting to a cell tower (mast) can affect the cell's signal strength. He contended that masts are designed to handle a certain number of connections at once, however, in most times; they tend to handle more than their designed capacity, since everyone wants to use his or her phone. The northern part of the study area has slightly less concentration of masts from both MTN and TIGO, possibly due to the forest reserve and low density residential areas located in the area. It also has some more dead zones. This could possibly be due to less population concentration and for that reason less revenue for the companies, making it unattractive for more investments in the area. Knowledge of the study area suggests that mast locations are more related to areas of higher population concentration. Typically areas like Accra Central, Abeka-Lapaz, Darkuma and Dansoman which have high population concentrations also have high concentration of masts.

The study results also indicated that although TIGO has three times fewer masts in AMA compared to MTN, TIGO's signal records are stronger on the field than MTN. Comparing field observation with the results from the model, the model predicts weaker signal for TIGO. In as much as TIGO has a stronger signal on the field, further probe reveals that MTN has three times more subscribers than TIGO. Data from the National Communications Authority (NCA) shows that the nationwide MTN voice call subscribers were 17,192,543 in 2016, compared to $5,213,398$ for TIGO in the same year. These numbers changed in 2017. By February 2017, MTN had increased its subscriber-base to $20,265,399$ people which constitutes $51.6 \%$ of all voice call subscribers in Ghana as compared to TIGO's 5,160,279 people (13.15\%). Although field signal strength appeared weaker for MTN, users find it more convenient, stable and audible in most places than TIGO. Other research works have shown that network usage and subscriber load is likely to cause weak signals. MTN's large subscriber-base may possibly be explained in terms of the number of masts of different height which makes it possible to send signals of different strength to fill dead zones. However, the size of the subscriber-base may have accounted for the weak signals experienced from the field. In discussion with some subscribers, they argued that the weaker MTN signal may likely be the result of the large subscriber-base which could have affect the signal strength. They alluded to the fact that the signal strength fluctuates between different times of the day and night, yet they prefer MTN to TIGO.

Furthermore, the spatial pattern of dead zones observed from the spatial modeling appears to be different from the field testing. Whereas spatial modeling suggests stronger signals for MTN than TIGO, field measurements proved otherwise. From the model, MTN had stronger signals in the central and mid-south, field measurement shows an overturned U-shaped ring (Figure 8) of high signal and other patches for MTN. For TIGO, field measurement indicates a stronger signal than the model. This however does not reflect in subscriber numbers and opinions of subscribers. Most mobile phone users prefer MTN to TIGO, which subscribers attributed to network quality, including voice call audibility, network provider charges, and frequent loss of prepaid credit and frequency of dropped calls.

Commenting on the impact of weak signal strength, sixty percent $(60 \%)$ of subscribers interviewed expressed worry about the dropped call rate and how it impacts their daily activities. Sixty (60\%) percent of subscribers were also worried about paying for mediocre quality services being offered by the two telecommunication companies in the country. Others were of the view that the NCA has not carried out its mandate creditably. This is because NCA is responsible for protecting consumers by ensuring that the telecommunication service providers perform up to the cost being paid by their subscribers. Again, subscribers expect NCA to compel providers to show areas where there are gaps in their network reception, to help subscribers make an informed judgment before subscribing for a service.

In conclusion, the study analyzed the signal strength of MTN and TIGO and concluded that the mast distribution within AMA shows positive spatial relationship with population concentration. Land use, which is well known to be a major source of impedance to signal propagation, is also found to be more related to population concentration and the concentration of masts seem to have overcome possible impedance from land use. MTN and TIGO have good signal strength across the AMA, although there are also large areas of relatively weak signal. MTN has a weaker signal compared to TIGO, judging from the field measurements, yet subscribers in general preferred MTN to TIGO, citing quality of service, including dropped call rate, cost and voice call audibility as the primary reasons.

The study recommends that MTN improves reception by erecting masts with higher heights than the existing ones. On TIGO's part, there is the need for further investigation into why subscribers complain about poor signals although field testing suggests better reception. Also, increased bandwidth for transmission can be of much help in terms of signal propagation. This allows for the transfer of a large amount of information (signal) to be transmitted over a connection. TIGO may improve by increasing the number of masts and the general distribution pattern. Although land use of AMA may play a negligible role on its own within AMA today, the land use pattern is gradually changing towards vertical developments (high rise buildings) which are more likely to affect signal strength soon in many localities in AMA. This development means that more buildings are going to interfere with 
signal propagation and network providers must act proactively.

Finally, the state institution, NCA, needs better understanding of the signal geography of Ghana to apply the appropriate sanctions and measures to ensure that the network providers provide quality service, which subscribers pay for instead of subscribers paying for unattained service.

\section{Reference}

1. Agbaraji, E.C., Ezeh , N.G. and Osuji , U., (2014). Cellular Mobile Signal Propagation; Effects of EIRP and Antenna Gain. Journal of Emerging Trends in Computing and Information Sciences 5(3):172-177.

2. AMA (2013). Environment and Social Management Framework (ESMF) for Sanitation and Water project for GAMA, December, 2012; Accra Ghana. Online available at: http://documents.worldbank.org/curated/en/176011468250869848/pdf/NonAsciiFileName0.pdf $(20 / 05 / 2016)$.

3. AMA, 2015. Sanitation and Environment. Accra Metropolitan climate and vegetation. Online available at: http://www.ghanadistricts.org/districts/ ?r=1\&_=3\&sa=3027\# (04/02/2016).

4. Anritsu (2003). Fundamentals of interference in wireless networks. Morgan Hill, CA: Spectrum master application note, pp.1-7.Retrieved from https://www.electrotest.co.nz/site/etl/Papers/Fundamentals_of_Interference_in_Wireless_networks.pdf (26/11/2018).

5. Communication Devices Inc (CDI) (2016). The basic of Cellular signal strength. http://www.commdevices.com (20/05/2017).

6. Ferris, B., Hahnel D. and Fox D., (2006). Gaussian Processes for Signal Strength-Based Location Estimation. In Proc. of Robotics Science and Systems, 2006. Pp1-8.

7. Ghana Statistical Service (GSS). (2012). 2010 Population and Housing Census: Summary Report of Final Results. Accra, Ghana: Ghana. Statistical Service

8. Guinness H. (2017). No bars? Here's everything that can affect your cellular signal strength.

Herndon, Virginia. Retrieved from https:/www.howtogeek.com/324525/everything-that-can-affect-your-cellularsignal-strength/ (26/10/2018).

9. Haslet, Christopher. (2008). Essentials of radio wave propagation. Cambridge University Press. 119120 ISBN 052187565X.

10. National Communication Authority (NCA) (2013). Telcos in Trouble, Retrieved from Daily Graphic on September, 2013.

11. National Communication Authority (NCA) (2017). Telecom Voice Subscription. NCA.org.gh 29/06/2017

12. Nkordeh N., Idachaba F., Bob-Manuel I. \& Oni O. (2016). Received signal strengt Measurement: Suboptimal handing-over. World congress on engineering I. London, U.K.

13. Owusu, B.A. (2018). An Assessment of Urban Vegetation Abundance in Accra Metropolitan Area, Ghana: A Geospatial Approach. Journal of Environmental Geography 11 (1-2), 37-44.

14. Patawari, N., O’Dea, R. J, Wang Y.,(2002) "Relative Location in Wireless Network", 2002. Accessed from IEEE Xplore Digital Library at http://ieeexplore.ieee.org/document/944560/ ISSN 1090-3038.

15. Person, D., (1992) “The Mobile Radio Propagation Channel”, New York: Halsted Press.

16. Radiation and Nuclei Safety Authority (RNSA), (2009). Radio Waves and Our Environment. https://www.stuk.fi/documents/88234/148243/radio-waves-and-our-environment-2009.pdf/f56dc4cf-963149a5-8bb2-dac0f7843fff. Accessed on 03/11/2018

17. Saveeda, P. et al.(2013), "Received Signal Strength (RSS) Calculation for GSM Cellular System at BSNL Pondicherry using Modified HATA Model”, International Journal of Science, Engineering and Technology Research (IJSETR). 2( 1) ISSN: 2278 - 7798

18. Shankari et al. (2014), Signal Strength Enhancer. International Journal of Industrial Electronics and Electrical Engineering 2(2): 16-18 ISSN: 2347-6982.

19. Singh B., Pallai S. and Rath S.K. (2012). A survey of cellular positioning techniques in GSM Networks. Odisha, India.

20. Telecoatennas, Accessed on the $23^{\text {rd }}$ of August, 2017. https://www.telcoantennas.com.au/site/poor-mobilenetwork-coverage-explained-weak-signal

21. Tepedepenlioglu, C., Abdi,A., Giannakis, G. B., \& Kaveh, M. (2001). Estimation of Doppler spread and signal strength in mobile communications with applications to handoff and adaptive transmission. Wireless Communication and Mobile Computing, 1(2), 221-242.

22. Viavi Solutions (2015). Interference in cellular networks: Intermodulation and frequency Refarming. California, U.S: White paper. Retrieved from https:/www.viavisolutions.com/en- us/literature/interferencecellular-networks-intermodulation-and-frequency-refarming-white-paper-en.pdf

23. Zheng, P. and Ni, L. (2010). Smart Phone and Next Generation Mobile. Computing Morgan Kaufmann series in networking. 